\title{
A BIOLOGIA MOLECULAR NO PROGNÓSTICO DO CARCINOMA DA TIREÓIDE
}

\author{
MOLECULAR BIOLOGY IN THE PROGNOSIS OF THYROID CARCINOMA
}

\author{
Aluizio Soares de Souza Rodrigues, ECBC-RJ' ${ }^{1}$
}

\section{INTRODUÇÃO}

O carcinoma da tireóide, como outros tumores malignos do organismo humano, origina-se de uma única célula, alterada por lesões dos genes que controlam a proliferação celular. O comportamento biológico do câncer tireoidiano é muito variado e embora, em sua maioria, apresente comprometimento clinicamente indolente, em alguns casos assume características agressivas, com invasão local e metástases à distância, que podem resultar no óbito do paciente.

Excluindo-se os carcinomas anaplásicos, invariavelmente fatais com qualquer tipo de tratamento, os diferenciados e os medulares admitem terapêuticas mais ou menos agressivas, de acordo com o comportamento biológico do tumor. Por isso, nas duas últimas décadas, diversos autores vêm procurando definir os fatores de risco que apresentam valor prognóstico na evolução destes tumores, especialmente na variedade diferenciada, tornando possível dividi-los em dois grupos: tumor de alto e de baixo risco, com condutas terapêuticas diferentes em cada grupo ${ }^{1-5}$.

Os fatores de risco avaliados baseiam-se em dados clínicos e anatomopatológicos que em análises multivariadas, mostraram-se independentemente responsáveis pelo prognóstico da doença. Entretanto, mesmo em pacientes considerados de baixo risco nestas classificações, alguns tumores podem eventualmente desenvolver comportamento mais agressivo. O estudo da expressão de oncogenes, de antioncogenes bem como de genes implicados na adesão celular e na disseminação tumoral, tem procurado aprimorar a avaliação prognóstica dos tumores tireoidianos a nível molecular ${ }^{6}$.

\section{ONCOGENES E ANTIONCOGENES NO CÂNCER DE TIREÓIDE}

Um melhor conhecimento da biologia molecular possibilitou o entendimento de alterações celulares que levam à formação e disseminação dos tumores. Diversos fatores estimulam a proliferação e a diferenciação celulares (genes estimuladores); outros são inibidores desta proliferação (genes supressores). Do inter-relacionamento adequado destes fatores resulta o funcionamento normal de órgãos e tecidos. As proteínas normais codificadas pelos genes estimuladores atuam na membrana celular, no citoplasma e no núcleo. Agem como fatores de crescimento, como receptores destes fatores, como proteínas envolvidas na transmissão de sinais dentro das células (mensageiros secundários) e como proteínas reguladoras nucleares. Na tireóide, os principais fatores estimulantes da proliferação celular e/ou de suas funções são o hormônio tireotrófico da hipófise (TSH), o fator de crescimento epidérmico (EGF), o fator de crescimento transformador $\propto(\mathrm{TGF} \propto)$ e o fator de crescimento semelhantes à insulina (IGF). Outros fatores menos importantes mas com ação semelhante, são o fator de crescimento fibroblasto básico (BFGF), a gonadotropina coriônica humana (hCG), o hormônio de crescimento $(\mathrm{GH})$ e o fator de crescimento do hepatócito (HGF) entre outros. Entre os genes supressores estão o $\mathrm{p} 53 \mathrm{e}$ o fator de crescimento transformador $\beta$ (TGF $\beta$ ).

Os fatores estimulantes codificam receptores específicos na célula que, ativados, modificam e transmitem o sinal a outras partes da célula através de diversas vias de transdução, que, na tireóide, são

1. Prof. Adjunto do Departamento de Cirurgia da Universidade Federal do Rio de Janeiro; Coordenador do Programa de Cirurgia Endócrina do Hospital Universitário Clementino Fraga Filho

Trabalho realizado no Hospital Universitário Clementino Fraga Filho da Universidade Federal do Rio de Janeiro. 
três principais: receptor/adenilciclase/proteinocinase, receptor/tirosinoquinase e receptor/cascata da fosfolipase $\mathrm{C}^{7-9}$.

Diversos genes agem no controle do crescimento celular e são chamados proto-oncogenes. $\mathrm{Mu}-$ tações, rearranjos estruturais ou amplificações genéticas dos proto-oncogenes provocam a perda do poder regulador da proliferação celular, levando a um crescimento desordenado e constante destas células. Nesta situação os proto-oncogenes são chamados oncogenes. A mutação de apenas um dos alelos do gene estimulante é suficiente para a formação do oncogene. Já nos genes supressores, a perda de seu poder inibidor exige inativação dos dois alelos (anti-oncogenes). Os oncogenes e antioncogenes são responsáveis pela formação dos tumores.

Entre os diversos fatores de crescimento, receptores celulares, transdutores e genes supressores que interferem no controle normal ou patológico do crescimento e proliferação das células tireoidianas, há três classes de oncogenes ativados que têm papel importante na iniciação e progressão dos tumores tireoidianos: os que codificam receptores associados à proteína $\mathrm{G}$ (ligadora do GTP), os que codificam receptores tirosinoquinase e os que codificam proteínas nucleares ${ }^{9-11}$.

\section{RECEPTORES ASSOCIADOS À PROTEÍNAS G}

Oncogenes ras - Todos os genes de família ras (H-ras, N-ras, K-ras) codificam proteínas de alto peso molecular designadas $\mathrm{p} 21$. Os oncogenes ras são ativados através de mutações nos codons 12, 13 e 61 e são encontrados em vários tipos de tumores tireoidianos, benignos ou malignos e ainda em lesões hiperplásticas não neoplásicas. Predominam no carcinoma folicular, em especial nos carcinomas de Hürthle 7,8 . Nos carcinomas papilíferos estão presentes entre $10 \%$ a $30 \%$ dos casos e nos foliculares em cerca de $50 \%{ }^{12-14}$. A maioria dos autores admite que os oncogenes ras atuam nas fases iniciais da carcinogênese, o que não é aceito por Goretzki ${ }^{15}$. Há discordância quanto aos membros da família ras envolvidos na gênese dos tumores tireoidianos: para alguns autores qualquer um dos tipos do oncogene ras são encontrados em incidências semelhantes, enquanto que para outros, ha prevalência do H-ras ou do N-ras nestes tumores ${ }^{7,12,15}$.
Oncogene gsp - Inicialmente encontrado em adenomas hiperplásticos, foram posteriormente identificados também em carcinomas diferenciados da tireóide, embora com prevalência relativamente baixa ${ }^{12,16}$. Goretzki et al ${ }^{15}$ mostraram em seus estudos a importância do oncogene $g s p$ nos carcinomas diferenciados da tireóide, principalmente na Alemanha, e sugerem influência da ingestão de iodo na expressão, maior ou menor, deste oncogene. Em carcinomas de Hürthle, a expressão elevada do $g s p$ tem sido encontrada entre $25 \%$ a $40 \%$ dos casos ${ }^{9}$.

Receptor do TSH (TSH-R) - É um receptor transmembrana ligado à proteína $\mathrm{G}$ e ativa a adenilciclase que converte o ATP em AMP cíclico, desempenhando papel importante em várias doenças. $\mathrm{Na}$ tireóide, a cascata sinalizadora do AMP cíclico está raramente envolvida na transformação maligna das células, mas é responsável através mutações no $g s p$ e no TSH-R, pela hiperfunção e crescimento da maioria dos adenomas foliculares tóxicos da tireóide ${ }^{13,16}$. Embora mais raramente, mutações no gene TSH-R tem sido encontradas em carcinomas diferenciados da glândula ${ }^{9,13}$. Com o aumento da indiferenciação do tumor, reduz-se a quantidade de TSH-R transcriptos ${ }^{7}$.

\section{RECEPTORES TIROSINOQUINASES}

RET oncogenes - Mutações destes genes são responsáveis pelas variedades familiares do carcinoma medular. As mutações ocorrem nos codons $630 \mathrm{e}$ 634 (exon 11), 609, 611, 618 e 620 (exon 10) no domínio das cisteinas do RET proto-oncogene e causam $80 \%$ a $90 \%$ do NEM-2A e da variedade familiar isolada destes tumores ${ }^{17,18}$. Mutações não cisteínicas do RET proto-oncogene ocorrem, mais raramente, no carcinoma medular familiar isolado, nos codons 768 , 790 e 791 (exon 13), 804 (exon 14), 821 (exon 15) e 918 (exon) 16 e também têm sido encontrados em carcinomas medulares inicialmente considerados como esporádicos ${ }^{18,19}$. Mutações no codon 918 (exon 16) são encontradas na síndrome NEM-2B.

Zedenius et al ${ }^{20}$ encontraram mutação somática do RET proto-oncogene em alguns carcinomas medulares de variedade esporádica (não familiar) ocorrendo a mutação no codon 918 exon 16, semelhante a mutação germinativa que ocorre na NEM 2-B.

Rearranjos do RET proto-oncogene, onde a porção tirosinoquinase do gene se une a outro gene de função desconhecida, no cromossoma 10q11 têm sido encontrados em cerca de $10 \%$ a $20 \%$ dos carci- 
nomas papilíferos e são designados RET/PTC protooncogene ${ }^{21}$. Nos carcinomas papilíferos após irradiação sofrida na infância, os RET/PTC protooncogenes ocorrem em até $60 \%$ dos casos.

Esses genes são específicos do carcinoma papilífero.

O RET/PTC oncogene é ativado por fusão com porções de outros genes formando três variedades: o RET/PTC-1, por fusão com o gene H4, de função desconhecida; o RET/PTC-2, por fusão com a subunidade TL $\propto$ da proteinocinase A; e o RET/PTC3 , por fusão com o gene ELE $1{ }^{9}$.

Sugg et al ${ }^{22}$ analisando a expressão do RET/ PTC nos microcarcinomas papilíferos, encontraram maior positividade deste oncogene $(77 \%)$ comparativamente aos tumores manifestos (45\%), com nítida predominância de variedade RET/PTC-1.

Se nos carcinomas papilíferos sem história de irradiação prévia o rearranjo da forma RET/PTC-1 é a predominante, nos tumores ocorridos após irradiação, como os encontrados após o acidente nuclear de Chernobyl, a variedade RET/PTC-3 foi a mais prevalente ${ }^{9,13}$. Baunacer et al ${ }^{23}$ em 39 tumores tireoidianos (19 Ca papilíferos e 20 adenomas) cujos pacientes receberam irradiação terapêutica prévia, encontrou incidência do rearranjo do RET/PTC semelhante à encontrada nos tumores pós Chernobyl (64\%) mas a alteração genética predominante foi o RET/PTC-1, tanto nos carcinomas (78\%) como nos adenomas $(45 \%)$. A razão por que a variedade do gene encontrado nos tumores pós Chernobyl difere de encontrada em tumores pós irradiação terapêutica é desconhecido. O rearranjo do RET/PTC encontrado em adenomas e em carcinomas papilíferos, pós irradiação terapêutica é idêntico. Nenhum rearranjo do gene foi encontrado em adenomas esporádicos, isto é, em pacientes não irradiados na maioria dos trabalhos publicados ${ }^{23}$, com excepeção do de Ishizaka et al ${ }^{24}$, em população Japonesa.

Oncogene trk - O gene trk é um receptor de membrana tirosinoquinase que se torna um oncogene em conseqüência de um rearranjo somático no cromossoma 1. Esse rearranjo só é encontrado no carcinoma papilífero esporádico (não irradiado) e nunca foi descrito em tumores ligados à indicação. Age como iniciador da lesão maligna e tem baixa prevalência ${ }^{13}$.

Oncogene c-met - O c-met codifica uma proteína tirosinoquinase identificada como o receptor do fator de crescimento do hepatócito (HGF) e que é um potente mitógeno de células epiteliais. A ativação do $c$-met se dá por amplificação do gene.

A expressão elevada do $c$-met é encontrada em $70 \%$ dos carcinomas papilíferos e baixa ou nula em outros tipos de carcinoma tireoidiano, segundo Suárez ${ }^{13}$. Farid et al ${ }^{7}$ também encontraram ativação do $c$-met em $70 \%$ dos carcinomas papilíferos mas encontraram-no presente em $25 \%$ dos foliculares; nos carcinomas anaplásico a expressão do $c$-met foi nula.

Expressão elevada do met/receptor do HFG nas células foliculares neoplásicas parece dever-se a uma relação parácrina entre o fator estimulante e o receptor já que o HGF é secretado pelas células parafoliculares tireoidianas ${ }^{25,}{ }^{26}$.

Oncogene c-erb - Dois membros da família do receptores tirosinoquinase o $c$-erbB e o $c$-erbB2 têm se mostrado com expressão elevada em vários cânceres de origem epitelial. $\mathrm{O} c$-erbB codifica os receptores do fator de crescimento epidérmico (EGF) e do fator de crescimento transformador $\propto(\mathrm{TGF} \propto)$. $\mathrm{O} c$-erbB2 é uma forma distinta mas intimamente relacionada ao $c$-erbB e codifica um tipo de receptor com atividade tirosinoquinase com ligante desconhecido. A expressão deste oncogene foi encontrada em tumores tireoidianos papilíferos em níveis não tão elevados como em outros tumores epiteliais mas duas a três vezes mais elevada que no tecido tireoidiano normal onde também é encontrado ${ }^{27}$.

Nenhuma amplificação ou rearranjo desses genes, contudo tem sido observada ${ }^{8,10,17}$. A positividade para o c-erbB2 foi maior nos tumores de grau histopatológico mais baixo que nos de grau mais elevado. Segundo Akslen et al ${ }^{28}$ esta diferença varia de $62 \%$ de positividade nos tumores de baixo grau de malignidade a $28 \%$ nos mais agressivos.

Oncogene BRAF - O oncogene BRAF, uma serina/threoninacinase, foi identificada por Davies $e t$ $a l^{29} \mathrm{em}$ diferentes tipos de câncer humano, especialmente nos melanomas e carcinoma do colon. Mais tarde, Kimura et al ${ }^{30}$ encontraram grande prevalência deste oncogene nos carcinomas papilíferos da tireóide (36\% dos 38 casos estudados) que consideraram a mutação genética mais comum nestes tumores. Resultados semelhantes foram descritos por Cohen et $a l^{31}$ que relatam mutação somática do BRAF, no exon 15 , em $69 \%$ dos carcinomas papilíferos estudados.

O BRAF age ativando a via de sinalização RAS/RAF/MEK/MAPK, um mecanismo biológico 
comum neste tipo de tumor tireoidiano ${ }^{31}$. A proteína RAF , uma serina-threonina proteinocinase, ativa a proteinocinase MEK que por sua vez ativa outra proteinocinase (MAPK). Ativação continuada ou inadequada desta via de sinalização resulta em proliferação anormal das células de vários tumores malignos. Das três variedades de RAF, o BRAF é a que tem maior afinidade com a MEK e é o mais eficiente na sua fosforilação ${ }^{29}$. Dois terços dos carcinomas papilíferos apresentam mutações dos genes RET/PTC, ras ou BRAF, mas sempre de forma isolada, sem sobreposição ou dependência entre eles embora Kimura et $a l{ }^{30}$ admitam que na predisposição ao carcinoma papilífero o gene ras agiria através do BRAF e no carcinoma folicular através de outro efetor ainda desconhecido. Entretanto, não é necessária mutação de gene ras para o desenvolvimento de células malignas com mutação do BRAF ${ }^{29,31}$. Mutações deste gene não são encontradas em lesões benignas da tireóide e, entre os tumores da glândula, o BRAF é exclusivo do carcinoma papilífero ${ }^{30,31}$.

\section{RECEPTORES ASSOCIADOS A PROTEÍNAS NUCLEARES}

Oncogenes $\boldsymbol{c}$-myc e c-fós - Os proto oncogenes $c$-myc e c-fós codificam proteínas nucleares e parecem ter papel importante no controle da proliferação celular.

$\mathrm{O} c$-fós tem se mostrado com expressão elevada em poucos tipos de tumores ao contrário do $c$ $m y c$ que apresenta reação positiva em grande número deles.

Na tireóide normal, há controvérsia quanto à expressão destes genes; Aasland et al ${ }^{27}$ encontraram-na elevada inclusive com altos níveis do $m R D A$ do $c$-myc e do $c$-fós, contrariamente a outros autores ${ }^{32,33}$ que relatam baixos níveis destes $m R D A$ em amostras de tecido tireoidiano normal. Embora a expressão do $c$-myc e de $c$-fós esteja elevada em alguns carcinomas tireoidianos, principalmente nos anaplásicos, nenhuma amplificação ou rearranjos destes proto oncogenes foi encontrada e a maioria dos estudos publicados não mostrou importância deles na tumorigênese dos tumores epiteliais da tireóide ${ }^{27,32,34}$. $O c$-myc parece ter participação importante na proliferação celular, como ocorre na Doença de Graves ${ }^{33}$.

\section{GENES SUPRESSORES (ANTIONCOGENES)}

Antioncogenes p53 - O gene p53 codifica uma fosfoproteína nuclear supressiva, no cromossoma 17 , controla o ciclo celular normal ${ }^{7,35}$ e inicia a apoptose, quando ocorre injúria severa do DNA. Mutações deste gene nos domínios dos exons 5 a 8 da molécula, modificam sua capacidade supressora e são encontradas em vários cânceres humanos. Nos tumores tireoidianos, o antioncogene p53 é prevalentemente encontrado no carcinoma anaplásico e também em alguns carcinomas pouco diferenciados $8,10,13,16,35$.

Diferentemente dos oncogenes ras e gsp, as mutações do p53 ocorrem em múltiplos sítios de suas regiões evolutivamente conservadas $9,13,14$. Além da perda de capacidade supressiva, as mutações de p53 dessensibilizam as células tireoidianas ao fator transformador $\beta$ (TGB $\beta$ ), um potente inibidor fisiológico da proliferação dos tireoicitos.

Antioncogene p15 - Goretzki et al ${ }^{36}$ mostraram que o gene MTS-2 codifica a proteína p15 que relaciona-se com a inibição da resposta das células malignas ao TGFb e admitem que o gene p15, quando modificado em sua molécula, perca esta capacidade inibitória e desta forma contribui para a tumorigênese tireoidiana como um antioncogene. Aqueles autores não encontraram deleções homozigóticas do MTS-2 nos tumores tireoidianos mas uma alteração genética (polimorfismo) identificados em 35\% dos carcinomas papilíferos e em $32 \%$ dos medulares contra apenas $15 \%$ dos DNA usados como contrôle.

Concluem que o gene supressor p15, quando alterado, tem influência não apenas na tumorigênese tireoidiana mas também na disseminação linfática dos tumores ${ }^{36,37}$.

Antioncogene RB - O gene RB deve seu nome ao fato de que mutações ou deleções de seus dois alelos são responsáveis pelo tumor retinoblastoma. Foi o primeiro gene supressor identificado e codifica uma fosfoproteína nuclear, a pRB, que atua na regulação do ciclo celular levando à inibição da transição da fase Gs a $S$ do ciclo e favorecendo a proliferação celular não controlada e a tumorigênese. Embora estas mutações sejam encontradas em vários tipos de carcinomas ${ }^{8,38}$, elas não parecem ter papel importante na patogênese dos tumores tireoidianos ${ }^{11}$. 


\section{PROGRESSÃO, INVASÃO LOCAL E FORMAÇÃO DE METÁSTASES DOS TUMORES TIREOIDIANOS}

Uma vez formado o tumor em que participaram oncogenes e/ou antioncogenes, a progressão, disseminação e diferenciação da lesão vai, em grande parte, depender de alterações de outros genes: genes que alteram a capacidade de célula em captar o iodo, tornando-se mais agressiva como o Nis $\left(\mathrm{Na}^{+} / \mathrm{I}^{-}\right.$ Symporter) ou gene transportador do iodo; os que mantém a adesividade entre as células, favorecendo a manutenção de-diferenciação celular e interferindo na metastisação como os genes b catenina, E-caderina e galactina-3; os que aumentam a captação da glicose pela célula maligna caracterizando maior desdiferenciação do tumor, como o GLUT-1 (gene transportador da glicose); os envolvidos no tempo da vida celular, como o gene da telomerase; os que promovem a neoformação vascular favorecendo o crescimento do tumor e a formação de metástases como o VEGF (fator de crescimento endotelial vascular); e os que possuem capacidade inibitória de metástases, como o gene nm-23.

Gene transportador do iodo (Nis) - Este gene desempenha importante papel na captação do iodo pelas células tireoidianas e sua baixa expressão nos carcinomas explica a baixa captação do iodo nestes tumores ${ }^{39,40}$. A ausência do Nis empresta às células neoplásicas uma maior capacidade proliferativa ${ }^{9}$.

$\mathrm{Na}$ Doença de Graves, a maioria das células foliculares expressam o Nis; na tireoidite autoimune o número de células Nis positivas é similar ao encontrado no tecido tireoidiano normal. No bócio nodular com hiperplasia, a positividade ao Nis é heterogênio mas o número de células positivas é maior que no tecido normal. Nos carcinomas bem diferenciados, papilíferos ou foliculares, o número de células Nispositivas é inferior ao do tecido normal e nos carcinomas pouco diferenciados é ainda menor ${ }^{41}$.

Genes $\beta$-catenina e E-caderina - São genes importantes na manutenção da atividade celular através da formação de um complexo b catenina/Ecaderina. Além da capacidade adesiva, estes genes têm influência na inibição da proliferação celular, a bcatenina bloqueando a via de sinalização Wnt através da adesão célula-célula e a E-caderina estimulando o aumento da expressão da proteína p27, um potente inibidor da proliferação celular ${ }^{42,43,44}$. Mutações nestes dois genes vão desregular aquelas ações, levando à redução das adesões celulares e provocando proliferação destas células, pelo desbloqueio da via Wnt e pela redução da proteína p27, e ainda formação de metástases.

A expressão reduzida de b-catenina e da $\mathrm{E}$ caderina tem sido descrita em tumores de vários órgãos, inclusive na tireóide, por diversos autores ${ }^{42,45}$ que destacam a importância desta redução na evolução da doença.

Gene da galectina 3 - As galectinas são lecitinas solúveis que se ligam a glicoconjugados que contêm galactose. As funções biológicas das galectinas não são ainda bem conhecidas mas sua distribuição em diferentes tecidos sugerem ter importância em vários processos fisiológicos. A galectina 3 está envolvida no crescimento, diferenciação e adesão celulares. Admite-se que desempenha também papel na transformação maligna das células tumorais e na produção de metástases.

Vários estudos mostraram expressão elevada da galectina em carcinomas epiteliais da tireóide; nos adenomas foliculares esta elevação não é encontrada ${ }^{46-48}$. Xu et al ${ }^{47}$ encontraram positividade para este gene em todos os 23 carcinomas, papilíferos e foliculares, analisados e em nenhuma das lesões benignas ou de célula de tecido tireoidiano normal. Em outros trabalhos a expressão elevada em 100\% dos carcinomas papilíferos foi confirmada mas o percentual foi menor nos carcinomas foliculares ${ }^{49}$. Vale lembrar que nestes últimos, a expressão elevada de galectina, embora predominantemente difusa, pode ocorrer de forma focal e neste caso podem ocorrer falsos negativos ${ }^{46}$. É fato reconhecido que a galectina 3 pode estar presente em células do sistema linfático (células de Langerhans) macrófagos, neutrófilos e "mast cells" mas Niedsiela et al ${ }^{50}$ foram os primeiros a referir a expressão elevada da galectina-3 na tireoidite de Hashimoto.

Gene da telomerase - A telomerase é uma enzima que mantém a estabilidade e integridade das porções terminais dos cromossomas compostos por telômeros. O encurtamento destes telômeros ocorre a cada ciclo celular e este progressivo encurtamento é responsável pela senescência e morte celular. A expressão do gene da telomerase é encontrada em todos os tecidos mas sua atividade se mantém reprimida no ciclo celular normal, com algumas excepções como nas células germinativas, tecido linfóide e epiderme, onde se mantém ativas ${ }^{51}$. Para que ocorra a imortalidade celular, como nas lesões tumorais, há 
necessidade da reativação da telomerase que mantém constante o comprimento dos telômeros. Desta forma, a atividade da telomerase reflete um genótipo altamente proliferativo e é encontrada em quase todos os tumores do organismo, inclusive na tireóide ${ }^{51,52}$.

Gene VEGF (Fator de crescimento endotelial vascular) - $\mathrm{O}$ crescimento dos tumores sólidos requer a formação de novos vasos sangüíneos (angiogênese) para sua irrigação adequada. Este processo é estimulado pela hipóxia e por diversos fatores ativadores do crescimento celular entre eles o VEGF que é secretado pelas células endoteliais e também por células neoplásicas. Tumores sólidos com mais de $2-3 \mathrm{~mm}$ necessitam de seu próprio suprimento sangüíneo. Esta neovascularização também viabiliza a metastização destas células de alto poder de crescimento, tornando a angiogênese fator determinante de progressão e da evolução do tumor ${ }^{7,9}$.

Soh et al ${ }^{53}$ demonstraram que a TSH eleva a expressão do VEGF no câncer da tireóide, facilitando o seu desenvolvimento. Estes autores confirmaram a elevação da expressão do gene nestes tumores, o que não foi encontrado no tecido tireoidiano normal.

Gene nm 23 - Stug et al ${ }^{54}$, em trabalho experimental, demonstraram a existência de um gene, $o$ nm 23, cujo mRDA apresentava-se em níveis elevados em tumores com baixo potencial de formar metástases e consideram que este gene ou colabora com outros genes inibitórios ou possui, ele mesmo, capacidade inibitória na formação de metástases. Posteriormente, Arai et al ${ }^{55}$ isolaram dois tipos do nm 23: o nm 23H1 e o nm $23 \mathrm{H} 2$ no carcinoma papilífero da tireóide. Embora o mDNA de ambas as formas mostrassem expressão elevada em carcinomas papilíferos com ou sem metástases apenas o nm $23 \mathrm{H} 1$ foi encontrado com expressão reduzida ou totalmente ausente nos linfonodos metastaticos dos casos estudados e ainda, que nos linfonodos não invadidos pelo tumor, a expressão do $\mathrm{nm} 23 \mathrm{H} 1$ permanecia elevada. Concluem que apenas a forma $\mathrm{H} 1$ tenha capacidade inibitória na invasão e metastisação da célula maligna mas que novos estudos devem ainda ser realizados para uma conclusão definitiva.

A capacidade inibitória do $\mathrm{nm} 23$ na formação de metástases foi confirmada em vários tumores humanos mas não encontrada em outros. Desta forma, o significado biológico de gene $\mathrm{nm} 23$ parece depender do tipo de tecido neoplásico. Na tireóide, os trabalhos são poucos e muitos vezes conflitantes.
Zafon et al ${ }^{56}$ estudando 94 casos de carcinomas diferenciados da tireóide não encontraram relação de baixa expressão do $\mathrm{nm} 23 \mathrm{H} 1$ com metástases em linfonodos cervicais mas, em carcinomas foliculares esta baixa expressão estava relacionada com a presença de metástases à distância e com menor sobrevida do paciente.

Gene GLUT-1 - As células malignas promovem um aumento da glicólise e da captação da glicose, esta última sendo mediada por proteínas transportadoras de glicose. O GLUT-1 é uma destas proteínas e exibe expressão elevada em vários tipos de câncer, inclusive da tireóide. Haber et al ${ }^{57}$ encontraram reação positiva para o GLUT-1 em 48\% dos carcinomas tireoidianos analisados e, com excepção de um caso de tireoidite, a reação foi negativa em todas as lesões benignas e no tecido tireoidiano normal. Os autores admitem que com a técnica do RT-PCR o percentual de positividade do GLUT-1 nos carcinomas possa ser ainda maior.

O fato de que a expressão do GLUT-1 está elevada principalmente em carcinomas tireoidianos pouco diferenciados e em metástases não captantes do $\mathrm{I}^{131}$ destes tumores, sugere que a presença do gene ocorra em tumores mais agressivos ${ }^{40,57}$.

Gene MUC-1 mucina - O MUC-1 pertence a uma família de glicoproteínas de alto pêso molecular. Modula a adesão celular e desta forma influencia na invasão tumoral e formação de metástases. É encontrada na membrana celular da maioria dos tecidos epiteliais. O MUC-1 que codifica uma proteína transmembrana é o gene mucina mais estudado e tem expressão elevada em vários tumores do trato gastrointestinal e respiratório. $\mathrm{O}$ envolvimento deste gene nos carcinomas tireoidianos é pouco conhecido.

Bièche et al ${ }^{58}$ encontraram reação imunohistoquímica positiva para a proteína MUC-1 tanto no tecido tireoidiano normal quanto nos adenomas e carcinomas, porém, mais acentuadamente nestes últimos. Verificaram também que esta reação positiva era limitada à membrana apical da célula e em apenas alguns casos de carcinomas encontrou reação positiva no citoplasma. Quanto ao mRDA do MUC-1, sua expressão esteve elevada em seis de 11 casos de carcinoma papilífero (55\%) enquanto que nos adenomas manteve-se nos níveis do tecido tireoidiano normal (10 casos). Dividindo os 11 casos de tumor papilífero em dois grupos, um de alto e outro de baixo risco, verificaram que nos de baixo risco a expressão do MUC-1 limitava-se a 
uma fina linha na membrana apical e reação citoplasmática só correu no grupo de alto risco. Concluem que há indícios de uma relação entre a expressão do MUC-1 e a agressividade do tumor mas admitem que estudos com maior número de casos e seguimentos mais longos são necessários para uma conclusão confiável.

\section{MUTAÇÕES GENÉTICAS NO PROGNÓSTICO DO CARCINOMA DIFERENCIADO DA TIREÓIDE}

DNA Nuclear - A quantidade de DNA nuclear das células tumorais relativamente à da célula normal tem sido referida como de importância na avaliação prognóstica do tumor. Tumores aneuplóides (quantidade do DNA maior que o das células normais) são reconhecidos como mais agressivos que os diplóides (quantidade do DNA igual à das células normais). Na tireóide, o valor prognóstico da ploidia do tumor é ainda questionável, principalmente quando é usada análise multivariada dos fatores de risco, onde não atinge valor significativo, isoladamente ${ }^{59,60}$. Vários estudos não demonstraram diferença de sobrevida dos pacientes com tumores tireoidianos aneuplóides ou diplóides ${ }^{28,61,62}$ embora outros autores reconheçam na ploidia, valor prognóstico ${ }^{63}$. Bäckdahl et al ${ }^{64}$ encontraram nos carcinomas papilíferos maior sobrevida nos tumores diplóides e Nishida et al ${ }^{35}$ maior incidência de metástases à distência no carcinoma folicular aneuplóide. Pasieka et al $^{65}$ acrescentando a ploidia do tumor à classificação de risco AMES, descreveu um grupo intermediário de risco composto por tumores considerados de baixo risco pela AMES que apresentam anaploidia e tumores de alto risco diplóides.

Maiores estudos são ainda necessários para que a ploidia do tumor seja incluída nas diversas classificações de risco existentes para os carcinomas diferenciados da tireóide.

\section{ONCOGENES E ANTIONCOGENES NO PROGNÓSTICO DO CARCINOMA DIFERENCIADO}

O papel desempenhado pelas mutações genéticas na formação dos tumores tireoidianos é hoje bem conhecida. Contudo, o valor destas mutações na avaliação prognóstica destes tumores não está ainda plenamente esclarecida.
O valor do oncogene RAS nesta avaliação não foi ainda confirmada; nos carcinomas papilíferos a sua prevalência é baixa, dificultando a avaliação. Apenas o trabalho de Hara et al ${ }^{12}$ sugeriu importância prognóstica do N-ras nestes tumores, confirmada por análise multivariada, mas a casuística analisada é pequena. Entre os carcinomas foliculares, onde o oncogene ras é mais prevalente, ele foi encontrado principalmente nos tumores de Hürthle, que tem comportamento mais agressivo.

A possibilidade de que os rearranjos do RET/ PTC tenham relação com a ocorrência de metástases cervicais no carcinoma papilífero é levantada por alguns autores ${ }^{66}$, principalmente pelo fato de terem sido encontrados em tumores classificados de baixo risco que apresentam metástases em linfonodos cervicais ${ }^{6,66}$. A importância prognóstica dos rearranjos no RET/PTC não foi confirmada nos trabalhos de Lam et al ${ }^{67}$ onde a prevalência do oncogenes foi de $85 \%$ nos carcinomas papilíferos em Hong Kong e nem no de Sugg et al ${ }^{6}$ que pesquisaram a presença do ras nos casos mais agressivos de carcinoma papilífero.

O gene gsp e o receptor do TSH raramente têm expressão elevada no carcinoma diferenciado. Mutações destes genes têm relação com os adenomas hiperfuncionantes e não são importantes, pelo que se conhece hoje, no prognóstico do tumor maligno tireoidiano.

Rearranjos do gene trk só foram encontrados no carcinoma papilífero e ainda assim, raramente. Não há indícios de sua influência no prognóstico da doença ${ }^{68}$.

Já o gene c-met, quando ativado, é mitogênico e motogênico e assim contribui para a agressividade do tumor e a formação de metástases ${ }^{7,13}$. O aumento da expressão do c-met confere maior sensibilidade à ação do fator de crescimento do hepatócito, que é um potente fator mitogênico e que é secretado pelas células parafoliculares tireoidianas ${ }^{26}$. Como a expressão do c-met se mostra elevada em $70 \%$ dos carcinomas papilíferos que, em sua maioria, são tumores de excelente prognóstico, o fato favorece a conclusão de que o oncogene não possui influência prognóstica, pelo menos no que se relaciona a sobrevida dos pacientes portadores destes tumores, opinião não compartilhada por Farid et $a l^{7}$ que o encontraram prevalentemente em tumores diferenciados clínica e patologicamente mais agressivos. 
A expressão elevada dos genes inibidores cerbB e c-erbB2, bem como dos respectivos RNA não é um evento comum nos carcinomas diferenciados da tireóide ${ }^{66}$. Embora esta elevação tenha sido relatada em casos de tumores pouco invasivos, sem metástases e se mostrado ausente nos tumores mais agressivos ${ }^{27}$, ${ }^{28}$, o real significado do c-erbB e do c-erbB2 no prognóstico dos carcinomas tireoidianos é ainda incerto ${ }^{66}$.

Mutações do gene BRAF são hoje reconhecidos como a alteração genética mais comum no carcinoma papilífero e são específicos deste tumor. Trabalhos sobre este oncogene são recentes e não há referência sobre a sua prevalência em tipos mais ou menos agressivos do tumor e assim sua importância prognóstica não pôde ainda ser avaliada.

Com relação aos oncogenes c-myc e c-fós, os estudos até agora realizados, não confirmam valor prognóstico a estes genes $27,28,33,34,69$.

As mutações do p53, alterando a característica inibitória do gene, são as alterações genéticas mais comuns nos cânceres humanos ${ }^{13,16}$. Na tireoidite este antioncogenes é encontrado com alta freqüência nos carcinomas anaplásicos e também nos pouco diferenciados. Nos diferenciados, elas são excepcionais e quando presentes sinalizam para a transformação do tumor para o tipo anaplásico ${ }^{10}$.

Desta forma, a demonstração da mutação ou imunorreatividade do p53 no tecido tumoral é indício seguro de agressividade do mesmo, que tem sido confirmado como fator independente de mau prognóstico, em análises multivariadas ${ }^{35}$.

Outros antioncogenes como o p15 e o RB não têm sido valorizados como fator de prognóstico no carcinoma diferenciado da tireóide. Apenas Goretzki et al ${ }^{36}$ sugerem participação do p15 na formação de metástases linfonodais cervicais no carcinoma papilífero.

O valor prognóstico da expressão dos genes envolvidos na proliferação celular, invasão local e formação de metástases no carcinoma diferenciado não está totalmente esclarecida embora, pelas respectivas ações que exercem nestes tumores, é de se supor que influenciam na evolução da doença e na sobrevida dos pacientes.

Dentre elas, o complexo E-caderina/catenina é o único que parece ter confirmado o seu valor prognóstico nos carcinomas diferenciados, conforme mostram analises multivariadas que incluem diversos fatores de risco, ao conferir valor independente do gene na previsão de pior prognóstico ${ }^{45}$.
Nas células tireoidianas malignas, a expressão do Nis é menor que nas células normais e é ainda menor nos tumores pouco diferenciados, que tem captação baixa ou nula do I ${ }^{131}$. Esta baixa captação indica maior agressividade do tumor mas nenhum trabalho refere-se à importância significativa da baixa expressão do Nis no prognóstico dos tumores tireoidianos.

Os trabalhos relativos ao gene inibidor $\mathrm{nm}$ 23 são ainda conflitantes. Arai et al ${ }^{55}$ encontraram expressão diminuída deste gene em linfonodos metastáticos de carcinoma papilífero, enquanto que os gânglios não invadidos pelo tumor, no mesmo paciente, mostravam expressão elevada do $\mathrm{nm} 23$. Conclui que o gene tem importância na prevenção de metástases cervicais naquele tumor. Já Zafan et al ${ }^{56}$ negam valor prognóstico do gene em carcinomas papilíferos mas nos foliculares mostraram relação entre a redução da expressão do nm 23 e a presença de metástases à distância e também com a sobrevida dos pacientes: nos casos que demonstraram reação positiva ao gene a sobrevida de 10 anos foi de $90 \%$ caindo para $40 \%$ nos casos de negatividade. Estes autores também compararam a imunorreatividade do $\mathrm{nm} 23 \mathrm{com}$ a classificação AMES na avaliação do risco do tumor e concluíram que o nm 23 é mais específico nesta avaliação porém menos sensível e ainda, que o $\mathrm{nm} 23$ tem maior valor preditivo do índice de sobrevida. Conclui ser o nm 23 importante fator de prognóstico no carcinoma folicular.

A galectina-3 interagindo com a proteína Mac2 na superfície da célula maligna provoca adesão dessas células levando à formação de êmbolos de células malignas para a formação das metástases ${ }^{46-48,70}$. Entretanto não ficou ainda provado que nos carcinomas diferenciados com metástases, a expressão da galectina-3 seja mais elevada que nos tumores sem metástases e o valor prognóstico deste gene nos carcinomas diferenciados permanece por definir.

Também o gene da telomerase, cuja atividade mantém a imortalidade de célula maligna, não tem ainda demonstrado sua importância como fator prognóstico no carcinoma diferenciado ${ }^{9}$, o mesmo acontecendo com o VEGF, apesar do papel que desempenha no crescimento e metastização tumoral e do valor prognóstico que tem demonstrado em outros tumores, como no da mama e nos melanomas.

As alterações da mucina celular podem influenciar na capacidade das células malignas em sua 
proliferação, na sua capacidade de reconhecimento imunológico e na adesão celular. Estudos recentes revelam que o aumento da expressão do gene MUC-1, o primeiro gene mucina humano descrito, está relacionado com pior prognóstico nos cânceres do pulmão, mama, estômago e colon. Na tireóide, Bièche et $a l^{58}$ associaram a expressão do MUC-1 nos carcinomas à agressividade do tumor, mas consideram necessários maiores estudos sobre a matéria.

Também o GLUT-1 foi relacionado com a agressividade tumoral, baseado no fato de a expressão do gene encontrar-se principalmente elevada nas variedades pouco diferenciadas e em suas metástases não captantes, do carcinoma da tireóide ${ }^{9,40,57}$.

Resumindo, diversas alterações genéticas têm sido encontradas no carcinoma diferenciado da tireóide e relacionadas ao seu prognóstico: algumas pela prevalência demonstrada nos tumores mais agressivos (ras, c-met, MUC-1. GLUT-1, c-erbB2, Nis); outros pela influência exercida na formação de metástases linfonodais do carcinoma papilífero (nm 23, RET/PTC) ou na metástases à distância do carcinoma folicular (nm 23). Contudo, apenas o complexo E.cedrrina/catenina e o p53 tiveram importância confirmada como fator de prognóstico independente, em análises multivariadas.

Como reconhecem vários autores, são ainda necessários estudos mais específicos e com seguimento mais prolongado dos pacientes, para definir com segurança a contribuição da biologia molecular na avaliação prognóstica do carcinoma diferenciado da tireóide.

\section{MUTACÕES GENÉTICAS NO CARCINOMA MEDULAR DA TIREÓIDE}

Berndt et al ${ }^{19}$ estudando famílias alemãs com carcinoma medular nas variedades NEM-2A e familiar isolado que não apresentavam as mutações habituais do RET proto-oncogene nos exons 10 e 11, sequenciaram o DNA destas famílias e também de tumores medulares considerados esporádicos (não familiares) e localizaram mutações no exon 13 (codons 790 e 791) em cinco daquelas famílias e em 11 casos de medular inicialmente considerados como esporádicos. Outros autores estudaram casos de carcinoma medular com mutações nos codons 790 e 791 e concluíram que nestes casos a ocorrência do tumor em seus portadores é baixa e a evolução bem mais be- nigna quando comparados com os que apresentam as mutações mais comuns, nos exons 10 e $11^{18,19,71}$.

A invasão de linfonodos é mais tardia nos tumores com mutações nestes codons (790 e 791): Gimm et $a l^{71}$ só encontraram linfonodos metastáticos em pacientes acima de 46 anos de idade e a invasão neoplásica se restringia ao compartimento cervical central.

Estes estudos sugerem que mutações nos codons 790 e 791 devam ser consideradas de bom prognóstico no carcinoma medular familiar e que os descendentes de famílias com este tipo de mutação possam ser apenas observados ${ }^{18}$ ou submetidos a tireoidectomia profilática somente após os oito anos de idade e com linfadenectomia só realizada nos pacientes com mais de 40 anos ${ }^{71}$. Vale contudo salientar, a raridade destas mutações.

Mais recentemente, mutações somáticas dos RET proto-oncogenes foram descritas no carcinoma medular esporádico (não familiar) nos codons 816 (exons 16) em cerca de $1 / 3$ dos casos ${ }^{20}$. Este achado sinaliza para um pior prognóstico e quando identificado no material colhido pela PAAF, exige tratamento mais agressivo ${ }^{20,72,73}$.

Alguns autores também reconhecem na anaploidia um fator de mau prognóstico no carcinoma medular da tireóide ${ }^{74}$.

Estes achados não modificam substancialmente a conduta hoje padronizada para o carcinoma medular mas sinalizam para uma linfadenectomia mais conservadora (apenas a cadeia cervical mediana) e uma tireoidectomia profilática mais tardia (após os oito anos) nos descendentes de portadores de tumores que apresentam mutações nos codons 790 e 791 que, como já foi dito, são raros.

\section{CONCLUSÕES}

Mutações, rearranjos ou amplificações em genes que interferem na formação, proliferação, invasão e disseminação de tumor maligno da tireóide são hoje bem conhecidas, mas a importância destes genes alterados no prognóstico da doença ainda não está definida. Embora vários deles predominem em tumores clinicamente mais agressivos, sua contribuição como fator isolado de risco, quando confrontados com outros fatores clínicos ou patológicos em análises multivariadas, não foi ainda confirmada, devido à escassez de trabalhos neste sentido e do número insuficiente de casos analisados. 
Desta forma, os conhecimentos atuais sobre a influência prognóstica das alterações genéticas no câncer tireoidiano, não contribuem, ainda, para a classificação destes tumores em tumor de alto ou baixo risco até aqui baseada em dados clínicos e patológicos e que tem orientado a conduta terapêutica, especialmente nos carcinomas diferenciados. A expectativa atual é de que com os avanços notáveis dos conhecimentos da biologia molecular já alcançados, possamos em breve aprimorar a classificação de risco no sentido de identificar, entre os tumores de baixo risco aqueles que podem apresentar um comportamento mais agressivo e dentre os de alto risco, aqueles capazes de evoluir favoravelmente, e assim programar com mais eficiência o tratamento agressivo para os tumores de grande risco e evitar esta terapêutica nos tumores certamente de evolução mais benigna.

Nos carcinomas medulares as alterações genéticas que indicam tumor menos agressivos são raras e quando presentes, apenas favorecem uma linfadenectomia menos radical.

\begin{abstract}
This overview examines some selected genetic mechanisms of cancer development. Strong evidence has been accumulated suggesting that alteration in either the struture or activity of proto-oncogene contributes to the development and for the maintenance of the malignant phenotype. Many factors are known to interfere with both normal and pathological controls of growth and differentiation of thyroid cells. Among them, some are oncogenes, like those encoding g-proteins (ras, gsp, TSH-R), encoding thyrosino kinases receptors (RET, trk, c-met, c-erb, BRAF) and encoding nuclear proteins (c-myc, e-fós). Others are antioncogenes (p53, p15, RB), by loss of the growth suppression ativity of the suppressive gene. Cancer cell invasion and metastasis are the major causes of morbidity and mortality in cancer patients. Many genes are involved in the mechanism of invasion and metastasis of thyroid tumors, like Nis, $\beta$-catenina, E-caderina, galectina-3, GLUT, telomerase, VEGT, nm-23. All these oncogenes, antioncogenes and tumor invasion and metastasis-related genes are analysed. Several clinical and prognostic factors have been proposed to identify patients at risk for the development of metastasis and death. The role of molecular genetics in this issue is discussed. However, other studies are needed to validate molecular alterations as an independent prognostic factor in thyroid cancer.
\end{abstract}

Key-Word: Molecular biology; Thyroid neoplasms; Prognosis; Oncogenes.

\section{REFERÊNCIAS}

01. Byar D, Green SB, Dor P, et al. - A prognostic index for thyroid carcinoma. A study of the E.O.R.T.C. Thyroid Cancer Cooperative Group. Eur J Cancer, 1985, 15(8):1033-1041.

02. Passler C, Prager G, Scheuba C, et al. - Application of staging systems for differentiated thyroid carcinoma in an endemic goiter region with iodine substitution. Ann Surg, 2003, 237(2):227-234, .

03. Kukkonen ST, Haapiainen RK, Franssila KO, et al. Papillary thyroid carcinoma: the new, age-related TNM classification system in a retrospective analysis of 199 patients. World J Surg, 1990, 14(6):837-842.

04. Hay ID, Bergstralh EY, Goellner JR, et al. - Predicting outcome in papillary thyroid carcinoma: development of a reliable prognostic scoring system in a cohort of 1779 patients surgically treated at one institution during 1940 through 1989. Surgery, 1993, 114(6):1050-1058.
05. Cady B, Rossi R - An expanded view of risk-group definition in differentiated thyroid carcinoma. Surgery, 1988, 104(6):947-953.

06. Sugg SL, Zheng L, Rosen IB, et al. - ret/PTC-1, -2, and -3 oncogene rearrangements in human thyroid carcinomas: implications for metastatic potential? J Clin Endocrinol Metab, 1996, 81(9):3360-3365.

07. Farid NR, Shi Y, Zou M - Molecular basis of thyroid cancer. Endocr Rev, 1994, 15(2):202-232.

08. Duh QY, Grossman EF - Thyroid growth factors, signal transduction pathways, and oncogenes. Surg Clin North Am, 1995, 75(3):421-437.

09. Ward LS - Bases moleculares para o diagnóstico e a terapêutica do câncer da tireóide. Rev Bras Clin Ter, 2000, 26(3):103-107.

10. Soares P, Sobrinho-Simões M - Recent advances in cytometry, cytogenetics and molecular genetics of thyroid tumours and tumour-like lesions. Pathol Res Pract, 1995, 191(4): 304-317. 
11. Hurwitz M, Sawicki M, Samara G, et al. - Diagnostic and prognostic molecular markers in cancer. Am J Surg, 1992, 164(3):299-306.

12. Hara H, Fulton N, Yashiro T, et al - N-Ras mutation: an independent prognostic factor for aggressiveness of papillary thyroid carcinoma. Surgery, 1994, 116(6): 10101016.

13. Suárez HG - Genetic alterations in human epithelial thyroid tumours. Clin Endocrinol, 1998, 48(5):531-546.

14. Lemoine NR, Mayall ES, Wyllie FS, et al. - Activated ras oncogenes in human thyroid cancers. Cancer Res, 1988, 48(16):4459-4463.

15. Goretzki PE, Lyons J, Stacy-Phipps S, et al. - Mutational activation of RAS and GSP oncogenes in differentiated Thyroid cancer and their biological implications. World J Surg, 1992, 16(4): 576-582.

16. Fagin JA - Genetic basis of endocrine disease 3: molecular defects in thyroid gland neoplasia. J Clin Endocrinol Metab, 1992, 75(6):1398-1400.

17. Wohllk N, Cote GJ, Evans DB, et al. - Application of genetic screening information to the management of medullary thyroid carcinoma and multiple endocrine neoplasia type 2. Endocrinol Metab Clin North Am, 1996, 25(1):1-25.

18. Fitze G, Schierz M, Bredow J, et al. - Various penetrance of familial medullary thyroid carcinoma in patients with RET proto-oncogene codon 790/791 germline mutations. Ann Surg, 236(5):570-575.

19. Berndt I, Reuter M, Saller B, et al. - A new hot spot for mutations in the ret proto-oncogene causing familial medullary thyroid carcinoma and multiple endocrine neoplasia type 2A. J Clin Endocrinol Metab, 1998, 83(3):770-774.

20. Zedenius J, Larsson C, Bergholm U, et al. - Mutations of codon 918 in the RET proto-oncogene correlate to poor prognosis in sporadic medullary thyroid carcinomas. J Clin Endocrinol Metab, 1995, 80(10):30883090.

21. Jhiang SM, Caruso DR, Gilmore E, et al. - Detection of the PTC/retTPC oncogene in human thyroid cancers. Oncogene, 1992, 7(7):1331-1337.

22. Sugg SL, Ezzat S, Rosen IB, et al. - Distinct multiple RET/PTC gene rearrangements in multifocal papillary thyroid neoplasia. J Clin Endocrinol Metab, 1998, 83(11):4116-4122.

23. Bounacer A, Wicker R, Caillou B, et al. - High prevalence of activating ret proto-oncogene rearrangements, in thyroid tumors from patients who had received external radiation. Oncogene, 1997, 15(11):1263-1273.

24. Ishizaka Y, Kobayashi S, Ushijima T, et al. - Detection of ret TPC/PTC transcripts in thyroid adenomas and adenomatous goiter by an RT-PCR method. Oncogene, 1991,6(9):1667-1672.
25. Zarnegar R, Muga S, Rahija R, et al. - Tissue distribution of hepatopoietin-A: a heparin-binding polypeptide growth factor for hepatocytes. Proc Natl Acad Sci USA, 1990, 87(3):1252-1256.

26. Ivan M, Bond JA, Prat M, et al. - Activated ras and ret oncogenes induce over-expression of c-met (hepatocyte growth factor receptor) in human thyroid epithelial cells. Oncogene, 1997, 14(20):2417-2423.

27. Aasland R, Lillehaug JR, Male R, et al. - Expression of oncogenes in thyroid tumours: coexpression of cerbB2/neu and c-erbB. Br J Cancer, 1988, 57(4):358363.

28. Akslen LA, Varhaug JE - Oncoproteins and tumor progression in papillary thyroid carcinoma: presence of epidermal growth factor receptor, c-erbB-2 protein, estrogen receptor related protein, $\mathrm{p} 21$-ras protein, and proliferation indicators in relation to tumor recurrences and patient survival. Cancer, 1995, 76(9):1643-1654.

29. Davies H, Bignell GR, Cox C, et al. - Mutations of the BRAF gene in human cancer. Nature, 2002, 417(6892):949-954.

30 KimuraET, Nikiforova MN, Zhu, et al. - High prevalence of BRAF mutations in thyroid cancer: genetic evidence for constitutive activation of the RET/PTC-RAS-BRAF signaling pathway in papillary thyroid carcinoma. Cancer Res, 2003, 63(7):1454-1457.

31. Cohen Y, Xing M, Mambo E, et al. - BRAF mutation in papillary thyroid carcinoma. J Natl Cancer Inst, 2003, 95(8):625-627.

32. Terrier P, Sheng ZM, Schlumberger M, et al. Structure and expression of c-myc and c-fos protooncogenes in thyroid carcinomas. Br J Cancer, 1988, 57(1):43-47.

33. Mizukami Y, Nonomura A, Hashimoto T, et al. Immunohistochemical demonstration of epidermal growth factor and c-myc oncogene product in normal, benign and malignant thyroid tissues. Histopathology, 1991, 18(1):11-18.

34. Wyllie FS, Lemoine NR, Williams ED, et al. - Structure and expression of nuclear oncogenes in multi-stage thyroid tumorigenesis. Br J Cancer, 1989, 60(4):561565.

35. Nishida T, Nakao K, Hamaji M, et al. - Overexpression of 553 protein and DNA content are important biologic prognostic factors for thyroid cancer. Surgery, 1996, 119(5):568-575.

36. Goretzki PE, Gorelov V, Dotzenrath C, et al. - A frequent mutation/polymorphism in tumor suppressor gene INK4B (MTS-2) in papillary and medullary thyroid cancer. Surgery, 1996, 120(6):1081-1088.

37. Hannon GJ, Beach D - p15/INK4B is a potential effector of TGF-beta-induced cell cycle arrest. Nature, 1994, 371(6494):257-261. 
38. Figge J, Bakst G, Weisheit D, et al. - Image analysis quantitation of immunoreactive retinoblastoma protein in human thyroid neoplasms with a streptavidin-biotinperoxidase staining technique. Am J Pathol, 1991, 139(6):1213-1219.

39. Arturi F, Russo D, Schlumberger M, et al. - Iodide symporter gene expression in human thyroid tumors. J Clin Endocrinol Metab, 1998, 83(7):2493-2496.

40. Lazar V, Bidart JM, Caillou B, et al. - Expression of the $\mathrm{Na}^{+} / \mathrm{I}^{-}$symporter gene in human thyroid tumors: a comparison study with other thyroid-specific genes. J Clin Endocrinol Metab, 1999, 84(9):3228-3234.

41. Caillou B, Troalen F, Baudin E, et al. $-\mathrm{Na}^{+} / \mathrm{I}^{-}$symporter distribution in human thyroid tissues: an immunohistochemical study. J Clin Endocrinol Metab, 1998, 83(11):4102-4106.

42. Wijnhoven BP, Dinjens WN, Pignatelli M - E-cadherincatenin cell-cell adhesion complex and human cancer. Br J Surg, 2000, 87(8):992-1005.

43. Garcia-Rostan G, Camp RL, Herrero A, et al. - -catenin dysregulation in thyroid neoplasms: down-regulation, aberrant nuclear expression, and CTNNB1 exon 3 mutations are markers for aggressive tumor phenotypes and poor prognosis. Am J Pathol, 2001, 158(3):987-996.

44. St Croix B, Sheehan C, Rak JW, et al, - E-Cadherindependent growth suppression is mediated by the cyclin-dependent kinase inhibitor p2 ${ }^{(\mathrm{KIP} 1)}$. J Cell Biol, 1998, 142(2):557-571.

45. von Wasielewski R, Rhein A, Werner M, et al. Immunohistochemical detection of E-cadherin in differentiated thyroid carcinomas correlates with clinical outcome. Cancer Res, 1997, 57(12):2501-2507.

46. Inohara $\mathrm{H}$, Honjo $\mathrm{Y}$, Yoshii $\mathrm{T}$, et al.- Expression of galectin-3 in fine-needle aspirates as a diagnostic marker differentiating benign from malignant thyroid neoplasms. Cancer, 1999, 85(11):2475-2484.

47. Xu XC, el-Naggar AK, Lotan R - Differential expression of galectin-1 and galectin-3 thyroid tumors. Potential diagnostic implications. Am J Pathol, 1995, 147(3): 815822 .

48. Inohara $\mathrm{H}$, Akahani $\mathrm{S}$, Koths $\mathrm{K}$, et al. - Interactions between galectin-3 and Mac-2-binding protein mediate cell-cell adhesion. Cancer Res, 1996, 56(19):4530-4534.

49. Fernández PL, Merino MJ, Gómez M, et al. - Galectin-3 and laminin expression in neoplastic and nonneoplastic thyroid tissue. J Pathol, 1997, 181(1):80-86.

50. Niedziela M, Maceluch J, Korman E - Galectin-3 is not an universal marker of malignancy in thyroid nodular disease in children and adolescents. J Clin Endocrinol Metab, 2002, 87(9): 4411.

51. Umbricht CB, Saji M, Westra WH, et al. - Telomerase activity: a marker to distinguish follicular thyroid adenoma from carcinoma. Cancer Res, 1997, 57(11):2144-2147.
52. Saji M, Westra WH, Chen H, et al. - Telomerase activity in the differential diagnosis of papillary carcinoma of the thyroid. Surgery, 1997, 122(6):1137-1140.

53. Soh EY, Sobhi SA, Wong MG, et al. - Thyroidstimulating hormone promotes the secretion of vascular endothelial growth factor in thyroid cancer cell lines. Surgery, 1996, 120(6):944-947.

54. Steeg PS, Bevilacqua G, Kopper L, et al. - Evidence for a novel gene associated with low tumor metastatic potential. J Natl Cancer Inst, 1988, 80(3):200-204.

55. Arai T, Watanabe M, Onodera M, et al. - Reduced nm 23-H1 messenger RNA expression in metastatic lymph nodes from patients with papillary carcinoma of the thyroid. Am J Pathol, 1993, 142(6):19381944.

56. Zafon C, Obiols G, Castellvi J, et al. - nm-23-H1 immunoreactivity as a prognostic factor in differentiated thyroid carcinoma. J Clin Endocrinol Metab, 2001, 86(8):3975-3980.

57. Haber RS, Weiser KR, Pritsker A, et al. - GLUT1 glucose transporter expression in benign and malignant thyroid nodules. Thyroid, 1997, 7(3):363-367.

58. Bièche I, Ruffet E, Zweibaum A, et al. - MUC1 mucin gene, transcripts, and protein in adenomas and papillary carcinomas of the thyroid. Thyroid, 1997, 7(5): 725-731.

59. Ruegemer JJ, Hay ID, Bergstralh EJ, et al. - Distant metastases in differentiated thyroid carcinoma: a multivariate analysis of prognostic variables. J Clin Endocrinol Metab, 1988, 67(3):501-508.

60. Cusick EL, Macintosh CA, Krukowski ZH, et al. Comparison of flow cytometry with static densitometry in papillary thyroid carcinoma. Br J Surg, 1990, 77(8): 913-916.

61. Joensuu H, Klemi P, Eerola E, et al. - Influence of cellular DNA content on survival in differentiated thyroid cancer. Cancer, 1986, 58(11):2462-2467.

62. Cusick EL, Ewen SW, Krukowski ZH, et al. - DNA aneuploidy in follicular thyroid neoplasia. Br J Surg, 1991, 78(1):94-96.

63. Bäckdahl M, Auer G, Forsslund G, et al. - Prognostic value of nuclear DNA content in follicular thyroid tumours. Acta Chir Scand, 1986, 152:1-7.

64. Bäckdahl M, Carstensen J, Auer G, et al. - Statistical evaluation of the prognostic value of nuclear DNA content in papillary, follicular, and medullary thyroid tumors. World J Surg, 1986, 10(6):974-980.

65. Pasieka JL, Zedenius Y, Auer G, et al. - Addition of nuclear DNA content to the AMES risk-group classification for papillary thyroid cancer. Surgery, 1992, 112(6): 1154-1160.

66. Sugg SL, Ezzat S, Zheng L, et al. - Oncogene profile of papillary thyroid carcinoma. Surgery, 1999, 125(1): $46-52$. 
67. Lam KY, Lo CY, Leung PS - High prevalence of RET proto-oncogene activation (RET/PTC) in papilary thyroid carcinomas. Eur J Endocrinol, 2002, 147(6):741745.

68. Musholt TJ, Musholt PB, Khaladj N, et al. - Prognostic significance of RET and NTRK1 rearrangements in sporadic papillary thyroid carcinoma. Surgery, 2000, 128(6):984-993.

69. Auguste LJ, Masood S, Westerband A, et al. Oncogene expression in follicular neoplasms of the thyroid. Am J Surg, 1992, 164(4):592-593.

70. Inohara H, Raz A - Functional evidence that cell surface galectin-3 mediates homotypic cell adhesion. Cancer Res, 1995, 55(15):3267-3271.

71. Gimm O, Niederle BE, Weber T, et al. - RET protooncogene mutations affecting codon 790/791: a mild form of multiple endocrine neoplasia type $2 \mathrm{~A}$ syndrome? Surgery, 2002, 132(6):952-959.
72. Zedenius J, Wallin G, Hamberger B, et al. - Somatic and MEN 2A de novo mutations identified in the RET protooncogene by screening of sporadic MTC. Hum Mol Genet, 1994, 3(8):1259-1262.

73. Frohnauer MK, Decker RA - Update on the MEN 2A c804 RET mutation: is prophylactic thyroidectomy indicated? Surgery, 2000, 128(6):1052-1058.

74. Bäckdahl M, Tallroth E, Auer G, et al. - Prognostic value of nuclear DNA content in medullary thyroid carcinoma. World J Surg, 1985, 9(6):980-987.

Endereço para correspondência:

Prof. Dr. Aluízio Rodrigues

Rua Smith Vasconcelos, 81

Cosme velho

22241-160 - Rio de Janeiro - RJ 